This is an Accepted Manuscript of an article published by Taylor \& Francis in Performance Research on 23/04/2020, available online: https://www.tandfonline.com/doi/abs/10.1080/13528165.2020.1736752 


\section{Fancy dress as an amateur craft}

Stephen Knott

As a fairly shy, retiring academic type I have seldom looked upon invitations to fancy dress parties with much glee. For much of my teenage and student years I managed to evade any serious engagement with fancy dress by wearing a genuine ushanka (Russian fur hat with ear flaps) worn by the Moscovite police force in the early 1990s that my older brother bought for me as a gift from his world travels. However, when I was employed at the Royal Academy of Arts (RA), my (admittedly uncomfortably hot) ushanka could not guarantee me immunity from the outpouring of creative masquerade in their annual Christmas celebrations. Wearing fancy dress, and more importantly, putting some effort into it, was compulsory. My kind colleague saved me the embarrassment of a terrible outfit that I had for the 'summer holiday' themed bash by marching me up Shaftesbury Avenue to the fancy dress store Angels to get a Hawaiian shirt and red make-up so that I could pull off the 'burned English tourist' look. The theme next year was tied to the popular From Russia (2008) exhibition. I was on safe ground: the ushanka came into service once again, this time with other Soviet memorabilia that I had started to collect.

It was not these annual festivities that piqued my interest in the complexity of fancy dress but instead the much smaller Halloween party that I was invited to by a colleague at the RA. At work, colleagues and I found out (probably through the internet) that Lionel Ritchie's song Hello was number one in the charts at the time of my birth and for some reason I was encouraged to dress up not as Ritchie, but as the clay model head that is sculpted in his image by his love interest in the music video for the song. With my enthusiasm for fancy dress at its height I bought a mask and a pack of modelling clay and managed to sculpt and affix something resembling a face (not anything like Ritchie's) to the smooth plastic surface. I remember the abject horror seen through my lumpen mask of some of the guests at the party tastefully decorated in vampire costumes. The host burst out in laughter. I spent the rest of the party trying to behave normally while the heavy mask (not at all kept in place by its cheap, thin elastic thread) dangled around my neck. 
I was confronted with the spectre of fancy dress once again when invited to a fancy dress wedding. The theme, appropriately, was famous couples. But as this involved my partner, we planned it well and ensured that we dress in considered costumes. Our friend was a potter so we dressed up as Bernard Leach and Lucie Rie, pioneering twentieth century studio potters whose friendship might have turned romantic at some point (Cooper 2012). Borrowing dirty aprons from the clay department at Liverpool Hope University where I was working at the time, buying a fake moustache, and wearing a white shirt, black tie and beige chinos made for a good outfit. My partner too carried the ethos of Rie with her with pinned back hair, and pale roll-neck. The only picture we've hung up in our flat of us both is from this event.

That both of these instances of fancy dress are connected by the versatile, imitative qualities of clay seems serendipitous, particularly given the fact that my partner and I have a strong academic interest in the material (Chandler and Knott 2016). But what strikes me when considering these two tales of (very) amateur fancy dress is how I inhabited the garb in two completely different ways: one with a sense of utter embarrassment and awkwardness, the other with an ease and comfort that explains why the framed picture remains on the wall. Then there is the more pressing question: did I feel more comfortable imitating the moustachioed Leach, with clothes that matched my wardrobe than a clay sculpture of Ritchie? Fancy dress affords chances for creative self-expression, but what are the rules, guidance and stipulations as to what is or is not appropriate? What is the value of the skills deployed in choosing or creating an outfit? How does fancy dress reflect the cultural (in)sensitivities of its day?

Fancy dress is a complex cultural practice; a performance, but one that is everyday and ubiquitous (all of us at least get invited to fancy dress parties); a craft, but one that ranges between bespoke dressmaking to low effort accessorising; creative, but also simultaneously guided. This article explores these tensions by tracing the roots of fancy dress back to the Victorian era, identifying how the practice was arbitrated by writers of guidance manuals, as well as the materials and networks of supply that made it possible to buy or make a 
fancy dress garment. Additionally I will highlight the importance of craft, or the making of garments, considering lo-fi, adhocist outfits made by inexpert hands alongside bespoke made-to-order examples.

The analysis presents an amateur craft as a complex, contradictory and culturally determined activity, an approach that counters the tendency to situate amateur practice as an example of genuine self-expression and creative autonomy. In design and craft this is manifest in anything from the celebration of the incredible skill possessed by men in sheds working on impossibly complex projects in their own time (Jackson 2010) to the emotional power of ad-hoc objects made by an untutored hand; an aesthetic challenge to professional, sterile perfection (Bjørkheim and Herbert 2018; Bartholomew 2012).

In performance studies, Holdsworth et al. talk of the recent 'amateur turn' in the discipline. The authors lay out three trajectories of amateur performance: the avant-garde manifestation with links to notable theatrical traditions, for example post-revolutionary Proletkult theatre in Russia discussed by Claire Bishop in Artificial Hells (Bishop 2012: 53-57); the conservatism of local theatre 'centred on questions of cultivation and education'; and amateurs as the 'preserver of endangered forms'. This model hints at the vast scope of amateur performance, but the remainder of the editorial authors veer towards a positive characterisation of amateurs and amateur groups as creating 'communit[ies] of interest', as a route to building lasting social bonds, as expressing genuine love for what they are doing, and almost de facto repositories of 'affect'. Like many artists and designers, academics enjoy fashioning an almost subversive conception of 'amateurism' as 'a point of resistance to a commodified culture or knowledge industry' or evidence of reaching out beyond the bounds of academic institutions (Holdsworth et al. 2017: 17).

This effort to reorient attention to an everyday, overlooked and marginal site of cultural production is completely welcome. Yet, quickly situating such practice as affective, creative and genuinely oppositional to the status quo clouds our vision of the greater complexity of amateur practice. We have to be alive 
to how amateur production can be ambiguous, idiosyncratic, private, conservative, compliant, weird and domestic, with a complex relationship to the acquisition and display of skill.

In this exploration of fancy dress I aim to highlight some of these complexities: namely, what was considered 'appropriate fancy dress' (primarily by authors of advice manuals) and how this reflected Victorian cultural attitudes particularly towards national and racial archetypes; and how the distinction between making your own or buying a garment 'made-to-order' impacted upon the wearer's 'performance' of their garment. What is clear is that donning a fancy dress outfit is not a simple matter of wearing one's affect on one's sleeve.

\section{Victorian fancy dress}

To start, we need establish historical context.

Fancy dress, in a form that we would recognise today, is essentially a Victorian invention. Unlike the Georgian masquerade that preceded it with its connotations of frivolity, excess and concealing the self beneath a mask, the Victorian fancy dress ball was a respectable and accessible amusement (Jarvis and Raine 1984: 5; Jarvis 1982: 37 Mitchell 2017: 297). By the last two decades of the nineteenth century there was an entire infrastructure supporting fancy dress balls and guiding individuals as to how they should dress for them. For a start, a number of authors wrote manuals that helped readers towards choosing a good outfit and assuaged the potential awkwardness of wearing unfamiliar garb. Ardern Holt was one of the most prolific among them. She wrote for The Queen, and her work Fancy Dresses Described, or What to Wear at Fancy Dress Balls, featuring the illustrations of Miss Lilian Young, went through several editions from the 1870s to the 1890s (Holt 1905b). The introduction to Holt's Gentleman's Fancy Dress (which also went through many editions) showed particular sensitivity to the reluctant fancy dress invitee: 
Many are deterred from accepting invitations to fancy balls by the difficulties which surround appearing in appropriate guise. My object has been to meet and facilitate these as much as possible. (Holt 1905a, 4)

Holt meets this aim by providing comprehensive lists (often illustrated) of different outfits in her books that were targeted at men and women, ranging from the 'Ace of Spades' and 'Indian Chieftain' to 'Henry VIII', and the 'New Woman' (with cutouts of bikes and golf clubs attached to an evening dress), and everything in between. All are accompanied by a brief description as to what is needed to put the outfit together, designed, as Holt states, to 'assist those who desire to make their costumes at home' (Holt 1905a, 1). It was a format copied by other authors and publishers. (Figure 1)

Holt's advice might well have been used by the crafty domestic dressmaker, but many of her books were published by Debenham \& Freebody - the precursor to today's Debenham's - which had a specialist counter making fancy dress costumes to order at a 'moderate price'. Advertisements for these services appear at the end and beginning of Holts' books, alongside those of various costumiers of London's theatreland, such as B. Burnet \& Co, L\&H Nathan, Samuel Brothers Ltd., and John Simmons \& Sons who were the historical costumiers to the royalty. These establishments primarily served the demands of the Covent Garden's theatres, but they were ready to satiate the appetite for fancy dress, if the price was right, and represent something of the precursor to places like Angels on Shaftesbury Avenue. This was a service particularly attractive to men lacking confidence in dressing up and unskilled in dressmaking. The ubiquity of advice and the sophistication of supporting infrastructure made it straightforward, for the urban socialite at least, to engage in fancy dress. As fashion historian Anthea Jarvis states the 'fancy dress mania was not by any means confined to the ultra-rich or ultra-fashionable, it manifested itself at all social levels, except the lowest, in the years between 1890 and 1914' (Jarvis 1982, 4).

\section{Appropriateness in Victorian fancy dress}


While fancy dress was on its way to becoming the commonplace activity we know today, the question of what constituted appropriate fancy dress bore down heavily on Victorian iterations of the practice. Being inexpert, fancy dress invitees - at least to the authors of guidance literature - needed to be shown how to choose, construct and wear their garments. This advice demonstrates the extent to which fancy dress was mediated - creativity expressed within strict boundaries.

Rebecca N. Mitchell in her authoritative article on Victorian fancy dress highlights how Holt, along with many other authors of guidebooks, was concerned about the issue of 'appropriateness' (Mitchell 2017, 298); in other words choosing or making a fancy dress that was historically accurate and commensurable to one's character and physiognomy. The commonest tropes of historical inaccuracy warned against by manual authors was using powdered hair for costumes outside the period of its vogue (from 1600-1795), Mrs C. S. Peel claiming that is was an 'abuse' to adopt this hair treatment for a 'Lady Jane Gray' or a 'Marguerite de Valois' (Peel 1905, introduction). The list of historically befitting beards in Holt's advice to gentleman - from 'swallow, sugar-loaf and spade beards' (Holt 1905a: 2) - is wide ranging enough to impress the Shoreditch hipster. And, of course, it was 'altogether incorrect' sporting of any facial hair while wearing a powdered wig (Holt 1905a: 3)

The expectation of historical precision is no surprise for an age infatuated with the past; Holt and Peel both suggested their readers engage in a bit of dress history to inform their choices. But seemingly more important was finding an outfit that best suited the physical and physiognomic characteristics of the wearer. Marie Bayard's advice for dressing up children is one exemplification of this tendency:

[fancy dress] should be chosen for children with some regards to their individual appearance and character. Thus, it is a failure to make a quiet, reserved boy, a clown or jester, or a delicate looking one Henry VIII, just as for girls it would be a mistake to choose a heavy-footed, 
slow child for a fairy, or a very great romp for a Quakeress or Queen of England. (Bayard 1888: 110)

Holt's advice to men is another:

... people at Fancy Balls often render themselves ridiculous because they assume characters in everyway opposed to their own personality [...] I have seen a man with fine presence, and a face that would have added dignity to the garb of a Venetian senator, arranged as a clown. (Holt 1905a: 3)

Mitchell positions sartorial foibles like these as constituting a 'misrecognition of the self' for the individual concerned (Mitchell 2017, 299). She argues that unlike the licentious Georgian masked ball, fancy dress had the potential to highlight rather than mask the innate characteristics of the wearer. Mitchell sees this in a positive light. She argues that fancy dress 'could be deployed with skill and with pleasure to reveal something meaningful about the nature of its wearer' (Mitchell 2017, 310). Similarly, Bradely Shope characterises fancy dress in the British Raj as 'uniquely meaningful,' highlighting a 'curious cosmopolitanism' that collapsed spatial difference and hierarchies and encouraged individuals to show off what they knew about the world and its different dress traditions, all to the background of 'Indian enchantment' (Shope 2011, 375-77).

Mitchell and Shope's conclusions here show the tendency, identified earlier, for academics to highlight amateur craft as self-expression, something definitely 'meaningful'. While fancy dress offered the space for a creative freedom from social expectations of dress, it was still a culturally determined activity. The selection of an 'appropriate' outfit, in the Victorian period at least, was not a simple reflection of self-expression or self-actualisation (to lean on Maslowian terminology) but related to the advice dispensed by Holt, Bayard and other commentators. Included in this Victorian construction of appropriateness was an expected sensitivity towards the colour of the wearer's skin. For example Peel advises in regard to peasant dresses: 
... a fair maiden should prefer the costumes of the North, especially if she happens to be tall and slender, and should leave the Spanish and Italian contardine to be represented by her small, dark sisters. (Peel 1905, introduction)

The success of an outfit and its selection, according to these how-to manuals, is dependent on an ability to map one's own look on a form of national, ethnic or racial stereotype that conforms to the Victorian taxonomical imaginary. This is not finding oneself in clothes, but aligning one's identity with that of an aggregated, rhapsodised, simplified and trivialised archetype. This is a conflation of individual with group identities that is common to fancy dress and has, I'm sure, unsettled fancy dress invitees throughout the ages. Recall the phenomenon of 'chav' fancy dress parties that became widespread from the early 2000s: well-heeled individuals - often students from red brick universities dressing in a garb associated with working class anti-social youth culture (with Vicky Pollard as the pin-up), to which Prince William (following a tendency among the royals towards fancy dress faux pax) fell afoul (Larcombe 2006; Jones 2016: 120).

The hypocrisies of Empire were writ large in 'appropriate' Victorian fancy dress. Peel's dispassionate advice above to find a fitting analogue to one's complexion, mirrored by Bayard and Holt, is rendered hypocritical by instructions on the broader use of make-up, and particularly by illustrations of outfits that require blackface. The appearance of 'Arab', 'Zulu', 'African Woman' and 'Nigger (Christy Minstrel)' on the lists of Holt, Bayard and Samuel Miller's guide to male character costumes, suggest that the racist impersonation inherent to minstrely - 'ubiquitous' according to David Olosuga in the music halls and popular theatre in the late nineteenth century - might have filtered through to more private domain of the fancy dress ball. (Olusoga 2016: 27079) It is hard to see how wearing a '[s]wallow-tailed coat with very long tail, and vest; all of a bright striped material, ornamented with large buttons [...] [h]igh collar and bright tie' (Miller 1884: 58) in imitation of a minstrel would be 
deemed appropriate in anything other than a culture steeped in notions of white superiority and racial hierarchisation.

Even the format of the fancy dress advice manuals lay bare the Victorian imperial impulse. The various outfit suggestions are lined up in long alphabetical lists (Figure 2); attempts to be comprehensive. They suggest that these publications had an appeal or their own, perhaps read as entertainment. Writer Brian Dillon suggests that the list is 'evidence of some vexation, a clue that something is missing' (Dillon 2017: 25). Readers are presented with options to map themselves against, but this taxonomic understanding is at odds with finding meaning or creative autonomy through costume. Instead the discourse of 'appropriate' fancy dress in the Victorian era subsumes frivolity, play, randomness and individuality into archetypes that convey control, understanding and accuracy. That is, before we consider how these garments are not merely selected, but made.

\section{Crafting fancy dress}

So far the analysis has focused on the selection of the appropriate outfit as the core labour involved in fancy dress. However, it is clear that fancy dress in the Victorian era (as well as before and after) involved a lot of craft. As mentioned earlier Holt intended her guidebook to be used by domestic dressmakers, but the manuals of Marie Bayard were much more practical and handson. Instead of bare descriptions, Bayard in her two books on fancy dress gave much more information about the materials needed for each outfit and how that material was to be manipulated (Bayard 1887; Bayard 1888). Her selection of outfits were determined by how easily there were to reproduce 'in either rich or inexpensive goods' and at the end of each outfit description Bayard made her readers aware that they could acquire flat patterns of each outfit from the Weldon's Ladies Journal office in the Strand (Bayard 1888, preface).

Bayard was the editor of Weldon's Ladies' Journal (1875-1954), one of the early accessible publications directed to home dressmakers, and it is in the 
Journal's 1886 volume where she first writes on fancy dress, presumably as a teaser for her upcoming publications. A blog by Marianne van Remoortel, a specialist in Victorian periodicals who is currently heading up a research project on women editors from 1710-1920, has unearthed information about 'The Mysterious Madame Bayard' who was integral to popularising dressmaking in Britain (Van Remoortel 2015). The Journal she edited is full of information about fashion and dressmaking and includes reader-to-editor conversations, information about new products and copious advertisements. Making fancy dress was just a small part of the explosion of home dressmaking in this period aided by the popularity and accessibility of the domestic sewing machine; the 'little Trojan horse' as Tim Putnam has described, enabling women to maintain a connection to sewing outside that of sweated labour (Putnam 1999: 280-1). Advertisements for sewing machines appear regularly in the fancy dress manuals that I looked at: Singer sewing machine publicity appears in Weldon's Ladies' Journal, and in Clayton's book The Amateur Stage: Plain instruction for its construction and arrangement (1871), Whight \& Mann of central London advertise the 'Alberta Unequalled Silent' 'with ornamental bronze stand' and 'The "Little Gem"' a sewing machine designed for those burning the midnight oil.

But what fancy dress was being made? Were women on sewing machines creating elaborate, detailed, and completed dresses like the ones illustrated in Holt's guidebooks or the resplendent examples from the Devonshire Ball in 1897 photographed with equal precision by James Lafayette (Michell 2017: 294). On occasion, maybe, but this depended on the ability to hire the best dressmakers - like the Covent Garden costumiers mentioned above. As fancy dress became more widespread among the middle classes, its practice was more lo-fi. As Jarvis writes:

In spite of the many ingenious suggestions offered by magazines and books, it seems likely that much fancy dress was basically fashionable evening dress with a slight "period" air, or with decoration or a few accessories added to suggest an allegorical character. (Jarvis 1982: 41) 
This is closer to my experience of fancy dress. Just wear what you normally do with a little adornment: white t-shirt and jeans with the addition of whatever prop or cut-out fits the theme. In their 1983 catalogue for the Museum of London exhibition Masquerade dress historians Celina Fox and Aileen Ribeiro state fancy dress's etymology is wedded to this notion of adornment, describing how the term initially referred to fashionable costume 'with some masquerade elements such as tinsel, gauze, scarves and flowers, thus conforming to the conventions, however slight, of disguise' (Fox and Ribeiro 1983: 9). They give the example of Goddess Diana being made by wearing jewellery in the form of 'arrows or crescent moons,' and the fancy dress manuals are full of other suggestions. Bayard states that a child's Mary Mary Quite Contrary outfit can be easily achieved through the 'addition of a small watering pot, rake, hoe, which may be made ornamented by covering with silver paper'; and Clayton suggests armour can be made 'of pasteboard, covered with tinfoil' (Bayard 1886: 133-4; Clayton 1871: 14-15).

These accessories and additions could easily be made or bought in the Victorian period with its sophisticated dressmaking suppliers, stationers and costumiers (Corina 1978: 45). These firms have been mentioned above but it is worth drawing attention to those who show particular attention to accessorising: Redmayne \& Co. of New Bond Street produce 'Dainty Accessories of all kinds' according to their advert (Holt 1898), Charles H. Fox of Covent Garden made all sorts of wigs and James White, also in Theatreland, focused solely on 'Imitation Gold and Silver Trimmings for Fancy Costumes' (Miller 1884). There was even occasional product placement within the description of how to produce specific outfits. Miller's guide includes a 'Skeleton' costume: tight black trousers and a tunic with a skeleton painted down the from, achievable, according to Miller, with 'luminous paint, or with Judson's glitterine paint.' (Miller 1884: 76.) (Figure 3) Bayard tells her readers that a 'capital assortment' of 'fancy muslins' and 'soft silks' for the 'Mary Had a Little Lamb' children's outfit were 'always to be found' at Liberty \& Co (Bayard 1888: 24).

Further evidence of the improvisatory nature of fancy dress from this period does exist. Jarvis draws attention to a report in The Lady's Pictorial in 1893 
that documented a fancy dress ball in the London department store Messrs Shoolbred \& Co. where 'charming costumes were the work of the wearers themselves' (Jarvis 1982: 41). Other evidence appears in the forms of images that offer a direct contrast from the crisp, well composed outfits illustrated in the works of Holt, Bayard, Miller and Peel: satirical cartoons for Punch and The London Illustrated News, and, as a more specific example, a couple of illustrations that appear in Charles Dickens' The Pickwick Papers' by Hablot K. Brown that show a number of less than impressive examples of fancy dress accessorising (Allingham 2012). The craft of fancy dress, both now and then, is more likely to be crafty - showing guile (or indeed poor taste) with the economy of a few material flourishes - than an example of resolved, tidy dressmaking.

Where this leaves the discussion of how crafting fancy dress impacted upon what was considered 'appropriate' is hard to tell. Holt prefers historical accuracy come what may, urging her reader to study dress rather than entertain 'theatrical ideas of periods which originate... in the fertile brains of modern days' (Holt 1905a: 3). Bayard seems more comfortable encouraging these same 'fertile brains' with her hands-on tips, information about patterns, materials and suppliers and more capricious suggestions. However, these are sources at one remove from the actual experience of designing, making and wearing outfits - and evidence of these activities are hard to come by. As a craft historian I am tempted to position self-making, whether ad-hoc or elaborate, as more 'creative' or 'meaningful' than judicious, informed selection of 'made-to-order' outfits. But that is too simplistic and does not account for the networks of production behind even the plainest fancy dress outfit.

A more compelling conclusion is to draw out how partial commitment to disguise, manifest through accessorising and adornment, is reflective of the amateur's lot more generally. The powdered wig, the oriental shawl, the tin-foiled prop - indeed, my ushanka - are suggestive of the amateur's quasi-commitment to performance, making and choosing the right or 'appropriate' outfit. They suggest participation, engagement and the desire to inhabit a different persona, but in a partial or slight way. This confuses the notion that amateur 
crafts, including fancy dress, are simple conduits of creative expression. Meaning and creativity is possible in amateur crafts, but the practice is tempered by social-cultural expectation, levels of skill (whether too high or too (ow), and limitations of resources, be they material, temporal or spatial. What is clear is that the academic impulse to tie amateur practice to affect, democracy and genuine expression can flatten the complexity of amateur practice and its specific elasticity within structures of everyday life.

\section{References}

Allingham, Philip V. (2012) 'Mrs Leo Hunter's Fancy-Dress Dejeuner' The Victorian Web, 27 Jan, http://www.victorianweb.org/art/illustration/phiz/pickwick/15.html, accessed 13 November 2019.

Bartholomew, Angela (2012) 'Ode to the Amateur: The Tactile Results of Jerszy Seymour's Amateur Workshop', Critical Issues in the Cultural Industries II, May, https://criticalissuesintheculturalindustries2.wordpress.com/studio-2/odeto-the-amateur/ accessed 30 September 2019.

Bayard, Marie (1886) 'Fancy Dresses for Children' Weldon's Ladies' Journal: 133--34.

Bayard, Marie (1887) Weldon's Practical Fancy Dress; or, suggestions for fancy and calico balls, London: Weldon \& Co. (Two series)

Bayard, Marie (1888) Weldon's Practical Fancy Dress for Children, London: Weldon \& Co.

Bishop, Claire (2012) Artificial Hells: Participatory Art and the Politics of Spectatorship, London: Verso.

Bjørkheim, Tora Endestad and Johnnny Herbert (2018) 'Sigve Knutson - The amateur craftsman' Norwegian Crafts, 9 Apr, http://www.norwegiancrafts.no/articles/sigve-knutson-the-amateur-craftsman, accessed 30 September 2019.

Chandler, Kimberley and Stephen Knott (2016) 'A Show of Hands: The Spectacle of Apprenticeship' in Christie Brown, Julian Stair and Clare Twomey (eds) Contemporary Clay and Museum Culture, London: Routledge, 105-114.

Clayton, Benjamin (1871) The Amateur Stage: plain directions for its construction and arrangement, at a small expense, London, Dean \& Son. 
Corina, Maurice (1975) Fine Silks and Oak Counters: Debenhams 1778-1978, London: Hutchinson.

Cooper, Emmanuel (2012) Lucie Rie: Modernist Potter, London: Yale University Press.

Dillon, Brian (2017) Essayism, London: Fitzcarraldo Editions.

Fox, Celina and Aileen Ribeiro (1983) Masquerade London: Museum of London.

Holdsworth, Nadine, Jane Milling and Helen Nicholson (2017) 'Theatre, Performance, and the Amateur Turn' Contemporary Theatre Review 27(1): 4-17.

Holt, Ardern (1898) Gentleman's Fancy Dress... Fourth Edition, London:

Edward Arnold.

Holt, Ardern (1905a) Gentleman's Fancy Dress... Sixth Edition, London: Edward Arnold.

Holt, Ardern (1905b) Fancy Dresses Described; or, what to wear at Fancy Dress Balls, London: Debenham \& Freebody.

Jackson, Andrew (2010) 'Constructing at Home: Understanding the Experience of the Amateur Maker' Design and Culture 2(1).

Jarvis, Anthea (1982) “There was a man from Bengal...” The Vogue for Fancy Dress, 1830-1950' Costume 16(1): 33-46.

Jarvis, Anthea and Patricia Raine (1984) Fancy Dress, Princes Risborough: Shire Publications.

Jones, Owen (2016) Chavs: The Demonization of the Working Class, London: Verso.

Larcombe, Duncan (2006) 'Future Bling of England' The Sun, 10 Apr, https://web.ar-

chive.org/web/20110602014012/http://www.thesun.co.uk/sol/homepage/news/article44322.ece, accessed 12 October 2019.

Miller, Samuel (1884) Male Character Costumes: A guide to gentleman's costumes suitable for fancy dress balls and private theatricals, London: S. Miller.

Mitchell, Rebecca (2017) 'The Victorian Fancy Dress Ball, 1870-1900,' Fashion Theory 21(3): 291-315.

Olusoga, David (2016) Black and British: A Forgotten History, London: Macmillan. 
Peel, Dorothy Constance (1905) Design for Fancy Dresses, etc., London: Beeton \& Co.

Putnam, Tim (1999) 'The Sewing Machine Comes Home' in Barbara Burman (ed.) The Culture of Sewing: Gender, Consumption and Homedressmaking, Oxford: Berg, 269-284.

Shope, Bradley (2011) 'Masquerading Sophistication: Fancy Dress Balls of Britain's Raj' Journal of Imperial and Commonwealth History 39 (3): 375-392.

Van Remoortel (2015) 'The Mysterious Madame Bayard' Agents of Change: Women Editors and Socio-Cultural Transformation of Europe 1710-1920 https://www.wechanged.ugent.be/blog/the-mysterious-madame-bayard/, accessed 12 October 2019.

\section{CAPTIONS}

Figure 1: 'Norwegian Fish Girl' in Marie Bayard (1887) Weldon's Practical Fancy Dress; or, suggestions for fancy and calico balls, London: Weldon \& Co: 81.

Figure 2: 'Index to illustrations' in Samuel Miller (1884) Male Character Costumes: A guide to gentleman's costumes suitable for fancy dress balls and private theatricals, London: S. Miller: 7.

Figure 3: Illustrations of 'Swiss Guard', 'Spanish Muleteer', 'Sardanapalus', 'Skeleton', and 'Sumggler', illustrated by R. L. Bööcks in Samuel Miller (1884) Male Character Costumes: A guide to gentleman's costumes suitable for fancy dress balls and private theatricals, London: S. Miller: 79. 